Research Article

\title{
Calculation of Transient Potential Rise on the Wind Turbine Struck by Lightning
}

\author{
Zhang Xiaoqing \\ National Active Distribution Network Technology Research Center, School of Electrical Engineering, Beijing Jiaotong University, \\ Beijing 100044, China
}

Correspondence should be addressed to Zhang Xiaoqing; xqzhang2@bjtu.edu.cn

Received 20 June 2014; Revised 23 July 2014; Accepted 23 July 2014; Published 31 August 2014

Academic Editor: Rui C. Marques

Copyright (c) 2014 Zhang Xiaoqing. This is an open access article distributed under the Creative Commons Attribution License, which permits unrestricted use, distribution, and reproduction in any medium, provided the original work is properly cited.

A circuit model is proposed in this paper for calculating the transient potential rise on the wind turbine struck by lightning. The model integrates the blade, sliding contact site, and tower and grounding system of the wind turbine into an equivalent circuit. The lightning current path from the attachment point to the ground can be fully described by the equivalent circuit. The transient potential responses are obtained in the different positions on the wind turbine by solving the circuit equations. In order to check the validity of the model, the laboratory measurement is made with a reduced-scale wind turbine. The measured potential waveform is compared with the calculated one and a better agreement is shown between them. The practical applicability of the model is also examined by a numerical example of a $2 \mathrm{MW}$ Chinese-built wind turbine.

\section{Introduction}

As wind power generation undergoes rapid growth, wind turbines (WTs) erected in large wind farms are regarded as a realistic alternative to conventional power plants. Due to their large height of towers, long rotating blades, and exposed locations, WTs can be easily struck by lightning. When a WT suffers a lightning stroke, a large lightning current will continue to flow from the attachment point to the grounding system and cause the transient potential rise on the WT. The high potential can sparkover the insulation distance and severely damage the WT components inside the structure. It can also give rise to the overvoltage surge that endangers the sensitive electronics and microprocessors in the WT control system. In the light of the serious problem arising from the transient potential rise, the protection design for the potential rise phenomenon has been paid more and more attention. In the protection design, the need exists for calculating the transient potential responses on the WT under lightning stroke. A few calculation methods were reported in literature [1-3]. In the previous methods, the tower, that is, the longest traveling path of lightning current on the WT, was modeled as a uniform transmission line. They are simple and easy to be adopted in the lightning transient calculation but incapable of calculating the transient potential responses in the different positions on the WT owing to their neglecting of the structural feature of the tower body. Recently, a more detailed method has been presented. This method represents the tower as a cage-like multiconductor system $[4,5]$ and can give the potential distribution on the $\mathrm{WT}$; however, it causes a significant increase in the circuit complexity. For an improvement on the lightning transient calculation of WTs, a simplified circuit model is proposed in this paper. The proposed model divides the tower into a series of hollow cylindrical sections and represents it as a $\pi$-type circuit chain instead of the complicated cage-like multiconductor system. Based on the simplified treatment for the tower, a WT is converted into an equivalent circuit that can give a complete description of lightning current path including the blade, sliding contact site, and tower and grounding system. Then, transient potential responses are obtained in the different positions on the WT by performing the transient calculation for the equivalent circuit. In order to confirm the validity of the proposed model, a laboratory experiment has also been carried out on a reduced-scale WT. 


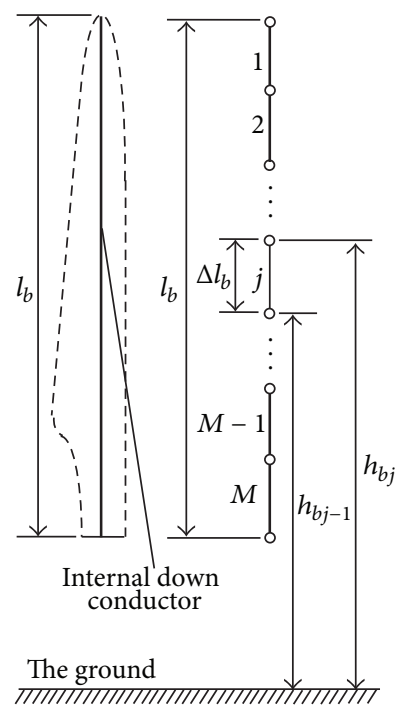

FIGURE 1: Segmentation of down conductor.

\section{Circuit Parameters}

2.1. Blade. An internal down conductor is usually installed inside the blade for conducting the lightning current from the attachment point to the hub, as shown in Figure 1. To take account of the propagation phenomenon of lightning current, the down conductor is divided into a suitable number of segments. The segment length $\Delta l_{b}$ needs to fulfill the following criterion [6]:

$$
\Delta l_{b}<\frac{1}{10} \frac{c}{f_{u}}
$$

where $c$ is the velocity of light and $f_{u}$ the maximum frequency likely to affect the system transient. An arbitrary segment $j(j=1,2, \ldots, M)$ in Figure 1 can be represented by a $\pi$-type circuit composed of resistance, inductance, and capacitance, as shown in Figure 2. The resistance $R_{b j}$ is estimated by [7]

$$
R_{b j}=\frac{\sqrt{\mu_{b} f_{u}}}{2 r_{b} \sqrt{\pi \sigma_{b}}}
$$

where $\mu_{b}$ and $\sigma_{b}$ are the material permeability and conductivity of the down conductor, respectively, and $r_{b}$ is the conductor radius. The inductance $L_{b j}$ is calculated by [5]

$$
L_{b j}=\frac{\mu_{0}}{4 \pi}\left(S_{j}+S_{j}^{\prime}\right)
$$

where $\mu_{0}$ is the permeability of free space $\left(4 \pi \times 10^{-7} \mathrm{H} / \mathrm{m}\right)$ and the two parameters in the round brackets are

$$
\begin{gathered}
S_{j}=r_{b}\left[2+\varphi\left(\frac{h_{b j}-h_{b j-1}}{r_{b}}\right)+\varphi\left(-\frac{h_{b j}-h_{b j-1}}{r_{b}}\right)\right] \\
S_{j}^{\prime}=r_{b}\left[\varphi\left(-\frac{2 h_{b j-1}}{r_{b}}\right)+\varphi\left(-\frac{2 h_{b j}}{r_{b}}\right)-2 \varphi\left(-\frac{h_{b j-1}+h_{b j}}{r_{b}}\right)\right],
\end{gathered}
$$
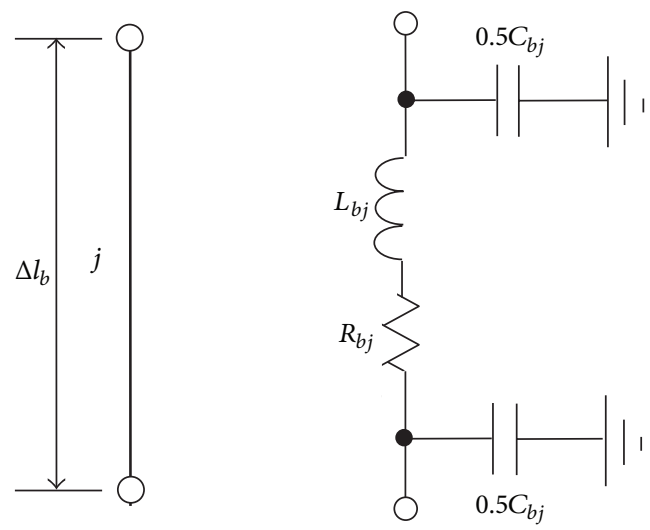

FIGURE 2: $\pi$-type circuit of a down conductor segment.

where $\varphi(\xi)=\xi \sinh ^{-1} \xi-\sqrt{1+\xi^{2}}$. According to the electromagnetic analogy [8-10], the capacitance $C_{b j}$ is determined by

$$
C_{b j}=\frac{\mu_{0} \varepsilon_{0}}{L_{b j}}
$$

where $\varepsilon_{0}$ is the permittivity of free space $\left[(36 \pi)^{-1} \times 10^{-9} \mathrm{~F} / \mathrm{m}\right]$.

2.2. Sliding Contact Site. The conductive path between the blade root and tower top is a sliding contact site and mainly includes the brushes, sliding contact systems, and main shaft bearings. The brushes have been widely used in the multimegawatt WTs to divert the lightning current from the blade root to the tower top. The circuit parameters of the brushes and main shaft bearings are simply represented as the contact resistance $R_{S}$ and equivalent capacitance $C_{r}[3,5]$, respectively. $C_{r}$ can be evaluated by the formula given in [11]. Since the nacelle is rarely tuning, the yaw bearing is not considered here. In view of the actual shunting route of lightning current, the sliding contact site is modeled as a simple parallel circuit, as shown in Figure 3.

2.3. Tower and Grounding System. An actual tower takes the shape of the hollow circular truncated cone, as shown in Figure 4, and is the longest traveling path of lightning current. As is the case in the blade, consideration of the propagation phenomenon of the lightning current needs the tower to be divided into a certain number of sections. Each section is approximately taken as a hollow cylinder and its length is determined by (1). An arbitrary section $k(k=1,2, \ldots, N)$ in Figure 4 can also be represented by a $\pi$-type circuit, as shown in Figure 5 . The resistance $R_{t k}$ is roughly evaluated by $[12,13]$

$$
R_{t k}=\left[1+\left(\sqrt{\frac{q}{2}}-1\right)\left(1-\frac{w}{r_{k}}-\frac{8}{4 \sqrt{2 q}-5}\left(\frac{w}{r_{k}}\right)^{2}\right)\right] R_{t k 0}
$$




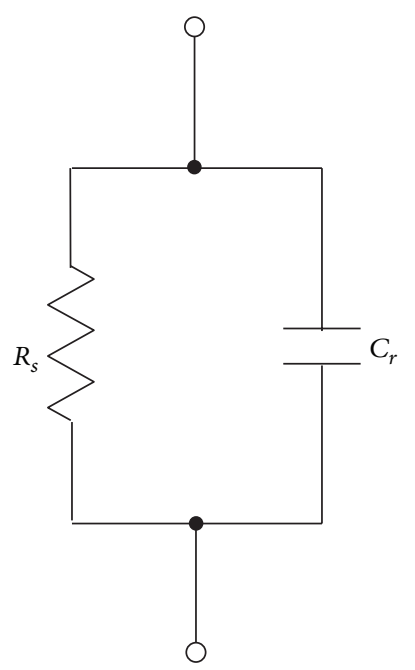

FIgURE 3: Parallel circuit of sliding contact site.
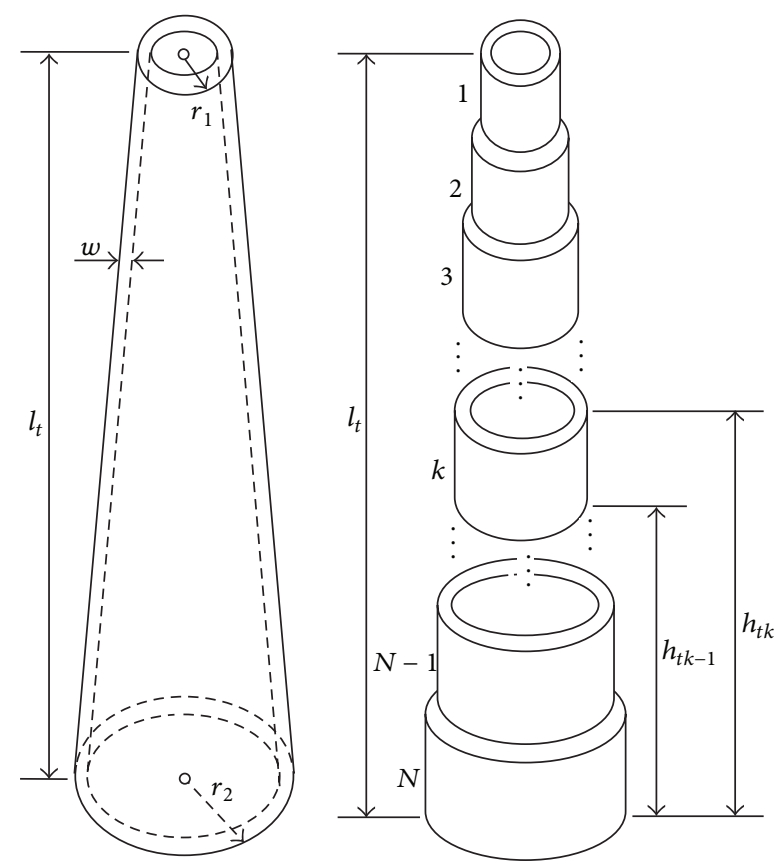

FIgURE 4: Approximate division of tower body.

where $q=2 \pi f_{u} \mu_{t} \sigma_{t} w^{2}$ and $R_{t k 0}$ is the DC resistance

$$
R_{t k 0}=\frac{h_{t k}-h_{t k-1}}{\sigma_{t} \pi\left[r_{k}^{2}-\left(r_{k}-w\right)^{2}\right]},
$$

where $\mu_{t}$ and $\sigma_{t}$ are the material permeability and conductivity of the tower, respectively. The inductance $L_{t k}$ is given by [14]

$$
L_{t k}=\frac{\mu_{0}}{2 \pi}\left[\ln \frac{2\left(h_{t k}-h_{t k-1}\right)}{r_{k}}-1-\frac{\mu_{t}}{\mu_{0}} \ln \eta\right],
$$

where $\eta$ is the geometrical factor depending on the ratio of $p=\left(r_{k}-w\right) / r_{k}$. Table 1 gives the values of $\eta$ in the range of
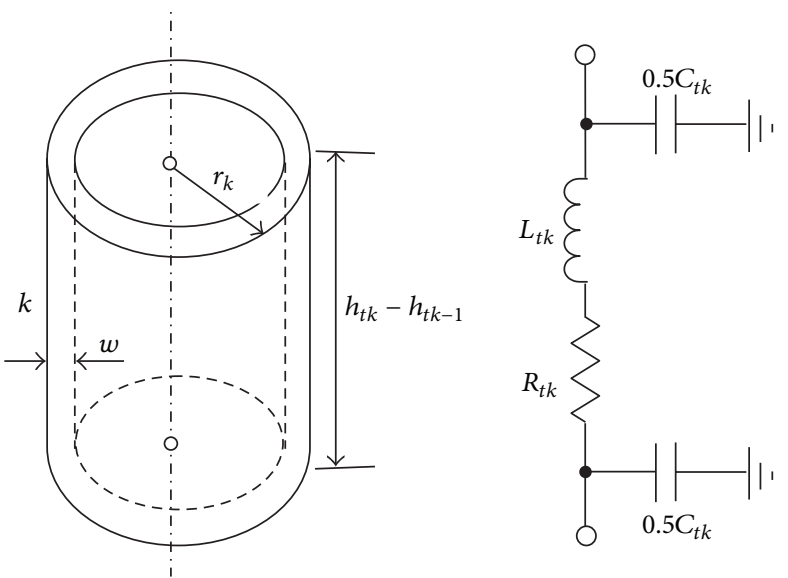

FIgURE 5: $\pi$-type circuit of a hollow cylinder section.

TABLE 1: Values of geometrical factor $\eta$.

\begin{tabular}{ccccccc}
\hline$P$ & 0 & 0.1 & 0.2 & 0.3 & 0.4 & 0.5 \\
$\eta$ & 0.7788 & 0.7825 & 0.7930 & 0.8087 & 0.8286 & 0.8519 \\
\hline$P$ & 0.6 & 0.7 & 0.8 & 0.9 & 1.0 & \\
$\eta$ & 0.8778 & 0.9058 & 0.9358 & 0.9672 & 1.000 & \\
\hline
\end{tabular}

$p=0 \sim 1$. By substituting $L_{t k}$ into (5), the capacitance $C_{t k}$ can be obtained.

For the sake of simplification, the grounding system is modeled as a grounding resistance $R_{g}[1,4]$. The value of $R_{g}$ is specified by the corresponding design standard [15].

\section{Circuit Model}

After obtaining the circuit parameters of the blade, sliding contact site, and tower and grounding system, a complete equivalent circuit can be built for a WT, as shown in Figure 6 . The lightning current source $i$ is injected to the top node of the equivalent circuit to simulate a lightning stroke to the blade tip and the impedance $Z$ in parallel with $i$ is the surge impedance of the lightning channel. For the capacitance in the equivalent circuit, as shown in Figure 7(a), its circuit equation is written as

$$
i_{C}=C \frac{d u_{C}}{d t} .
$$

Integration of (9) between $[t-\Delta t, t]$ gives

$$
\int_{t-\Delta t}^{t} i_{C} d t=\int_{t-\Delta t}^{t} C \frac{d u_{C}}{d t}
$$

where $\Delta t$ is the time step size. By means of the trapezoidal rule, the integration is evaluated by

$$
\frac{i_{C}(t-\Delta t)+i_{C}(t)}{2} \Delta t=C\left[u_{C}(t)+u_{C}(t-\Delta t)\right] .
$$

This can be rewritten as

$$
i_{C}(t)=\frac{1}{R_{C}} u_{C}(t)+I_{C}(t-\Delta t),
$$



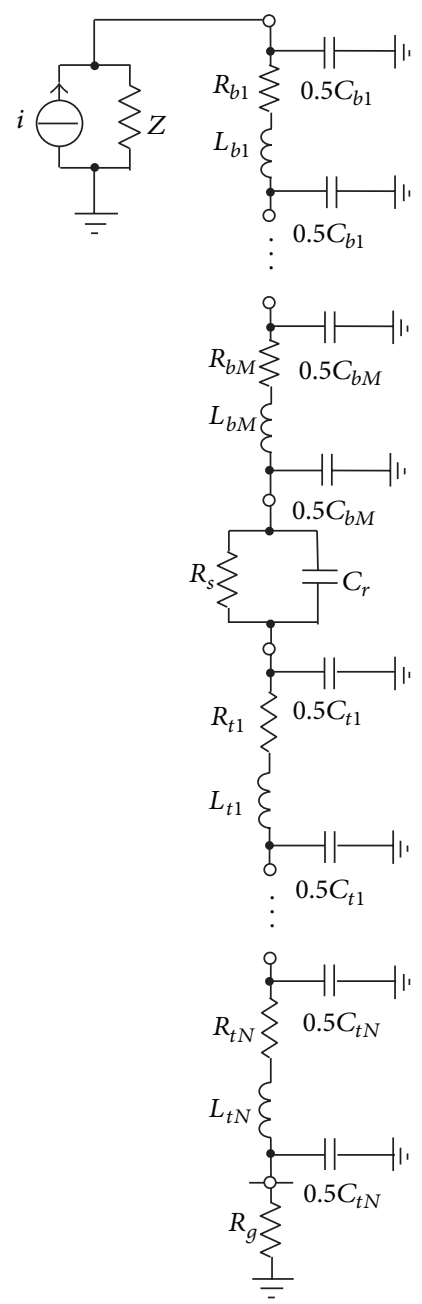

FIgURE 6: Complete equivalent circuit of a WT.

where

$$
\begin{gathered}
R_{C}=\frac{\Delta t}{2 C} \\
I_{C}(t-\Delta t)=-\frac{u_{C}(t-\Delta t)}{R_{C}}-i_{C}(t-\Delta t) .
\end{gathered}
$$

The circuit model for (12) is a parallel circuit unit, as shown in Figure 7(b). For the resistance-inductance $(R-L)$ branch in the equivalent circuit, as shown in Figure 8(a), its circuit equation is

$$
u_{R L}=R i_{R L}+L \frac{d i_{R L}}{d t}
$$

that is

$$
\frac{d i_{R L}}{d t}=\frac{1}{L}\left(u_{R L}-R i_{R L}\right) .
$$

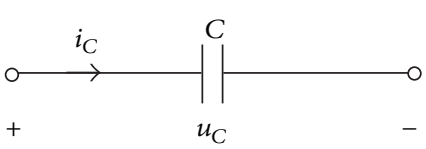

(a)

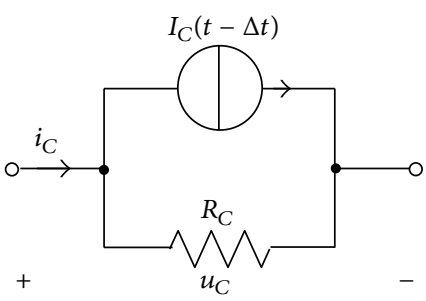

(b)

FIgURE 7: Discretization representation of capacitance. (a) Capacitance and (b) parallel circuit unit.

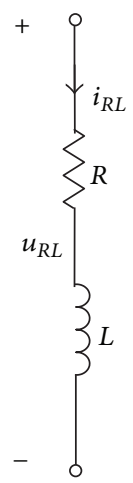

(a)

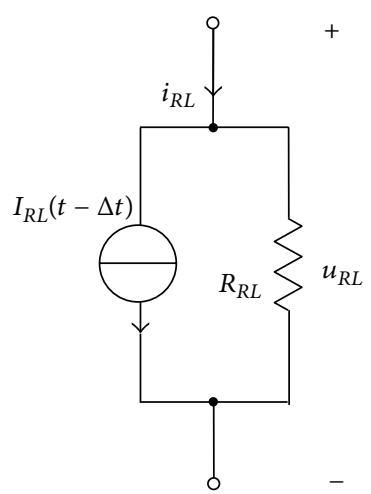

(b)

FIGURE 8: Discretization representation of $R-L$ branch. (a) $R-L$ branch and (b) parallel circuit unit.

Using the trapezoidal rule to integrate both sides of (15) between $[t-\Delta t, t]$ yields $[16]$

$$
\begin{aligned}
i_{R L}(t) & -i_{R L}(t-\Delta t) \\
= & \frac{1}{L} \frac{u_{R L}(t)-R i_{R L}(t)+u_{R L}(t-\Delta t)-R i_{R L}(t-\Delta t)}{2} \Delta t .
\end{aligned}
$$




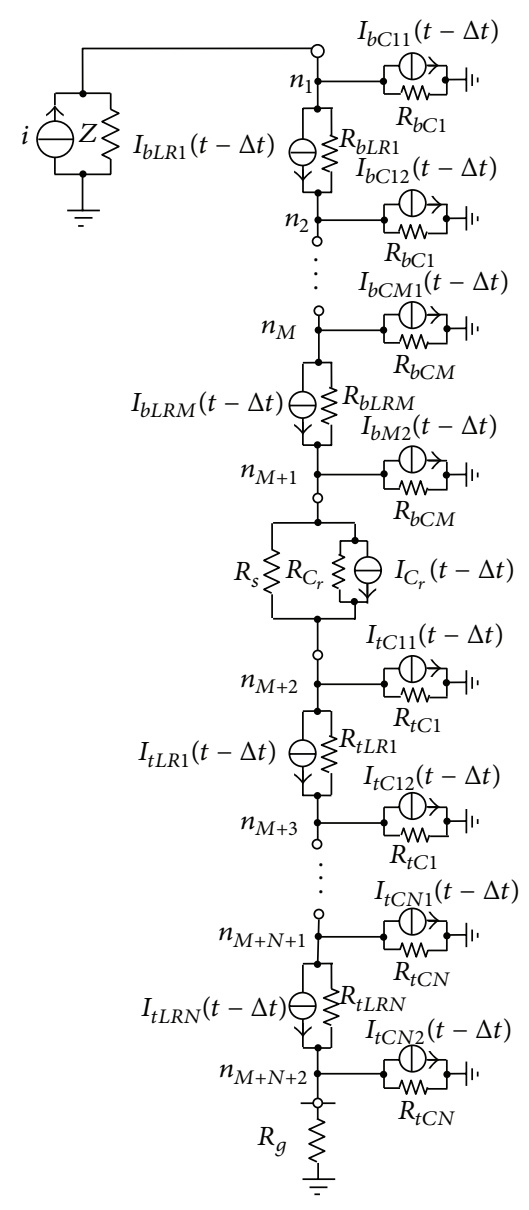

FIgURE 9: Time discretization circuit.

Rearranging the terms in (16) leads to

$$
i_{R L}(t)=\frac{1}{R_{R L}} u_{R L}(t)+I_{R L}(t-\Delta t),
$$

Where

$$
\begin{aligned}
R_{R L}= & R+\frac{2 L}{\Delta t}, I_{R L}(t-\Delta t) \\
= & \frac{1}{R_{R L}} u_{R L}(t-\Delta t) \\
& +\frac{1}{R_{R L}}\left(R_{R L}-2 R\right) i_{R L}(t-\Delta t) .
\end{aligned}
$$

In terms of (17), the parallel circuit unit is depicted for the $R-L$ branch, as shown in Figure 8(b). The current sources $I_{C}(t-\Delta t)$ and $I_{R L}(t-\Delta t)$ are known from the values for the preceding time step. After all capacitances and $R-L$ branches are replaced by their respective parallel circuit units, Figure 6 is further converted into a time discretization circuit consisting only of resistances and current sources, as shown in Figure 9. The node voltage equations are set up for the time discretization circuit

$$
\mathbf{G}_{n} \mathbf{u}_{n}=\mathbf{i}_{n}
$$

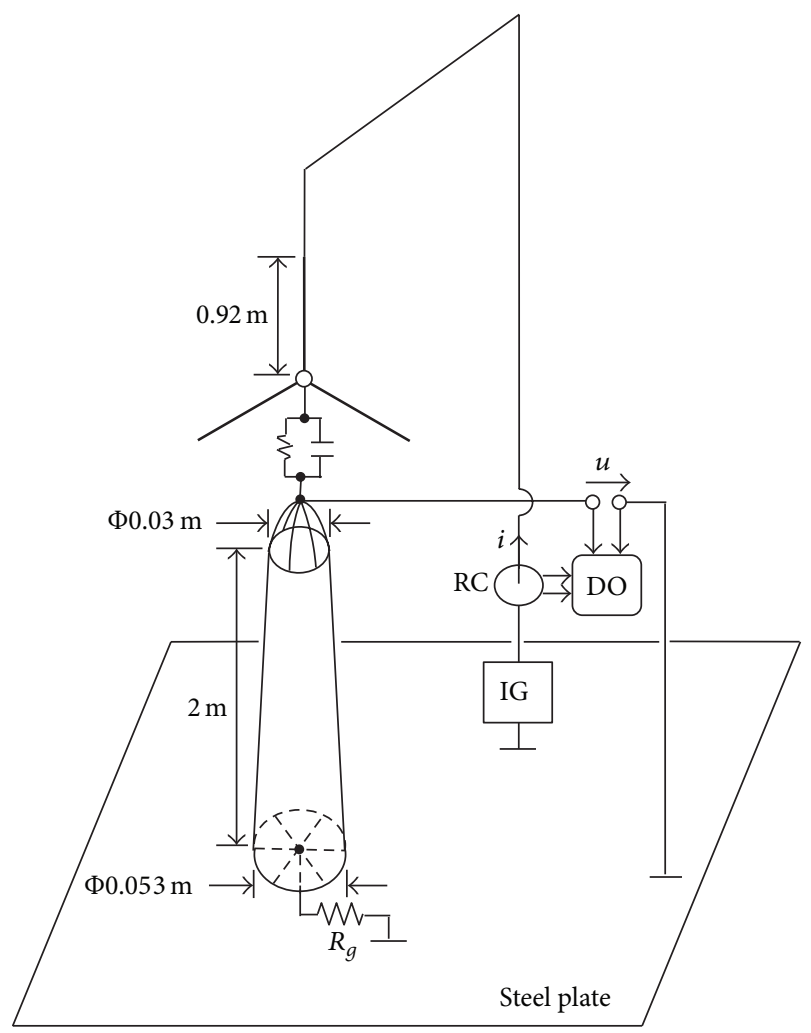

FIgURE 10: Experimental setup (RC: Rogowski coil; DO: digital oscilloscope; IG: impulse generator).

where $\mathbf{G}_{n}$ is the node conductance matrix, $\mathbf{u}_{n}$ the node voltage vector, and $\mathbf{i}_{n}$ the node current source vector. At $t=0$, all capacitances and inductances are set in zero initial conditions. The node voltage vector $\mathbf{u}_{n}\left(\left[u_{n 1}, \ldots\right.\right.$ , $\left.u_{n M}, \ldots, u_{n M+N+2}\right]^{T}$ ) is obtained by solving (19) in each time step $[17,18]$. Thus, the transient potential responses can be given for the different positions on the WT under lightning stroke.

\section{Experimental Verification}

A reduced-scale WT is built in the high voltage laboratory. Its dimensions are shown in Figure 10. The grounding resistance $R_{g}$ is $4 \Omega$. The fast impulse current provided by an impulse generator is injected to the blade tip. The lead wire for measuring the transient potential is stretched perpendicular to the current lead wire and grounded (connected to the steel plate) at a point $8.0 \mathrm{~m}$ apart from the reduced-scale WT, which can restrain the electromagnetic induction between the two wires. In the experimental measurement, the current and potential signals are recorded by a digital oscilloscope. The measured waveforms of injected current and transient potential at the tower top are shown in Figure 11, where the corresponding waveform calculated from the circuit model proposed above is also given for comparison. It can be seen from Figure 11 that the calculated waveform is close to the measured one. 


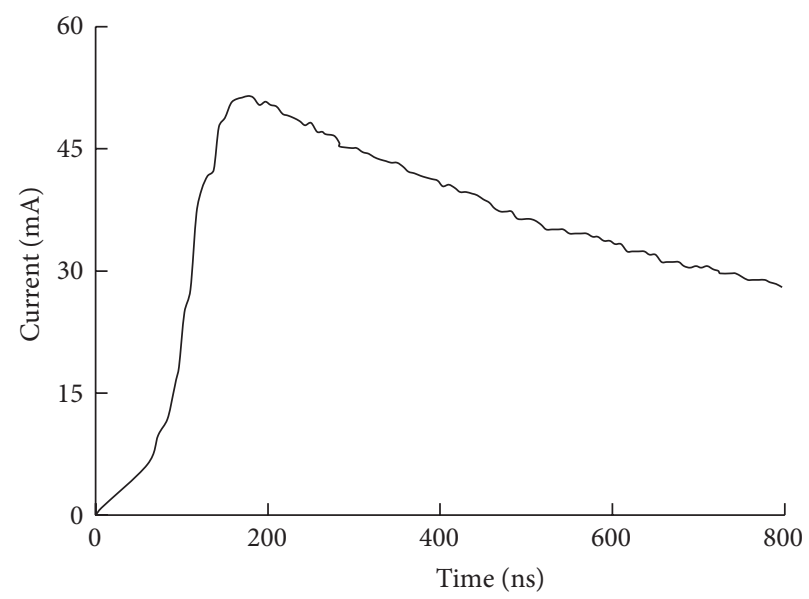

(a)

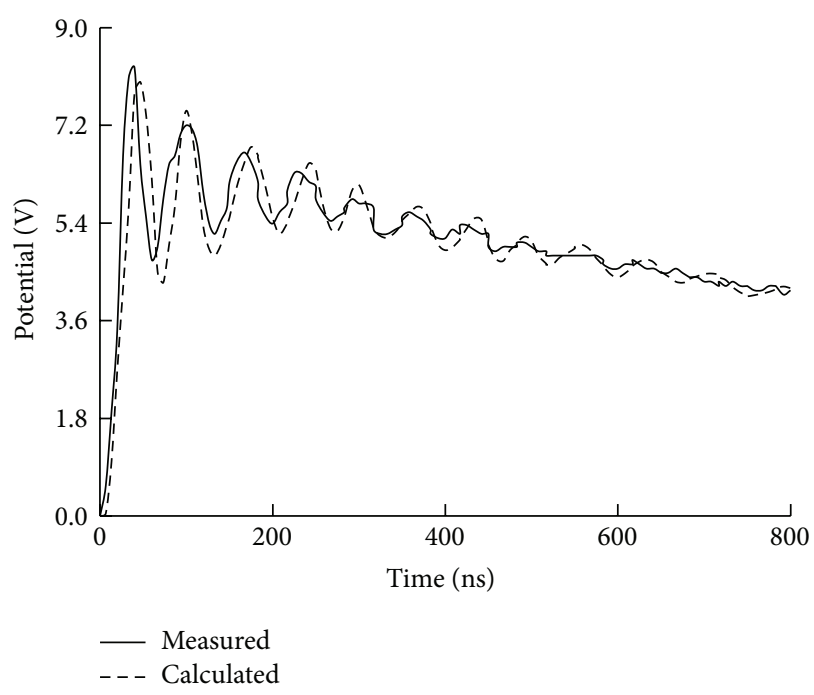

(b)

FIGURE 11: Comparison between measured and calculated waveforms. (a) Injected current. (b) Transient potentials at tower top.

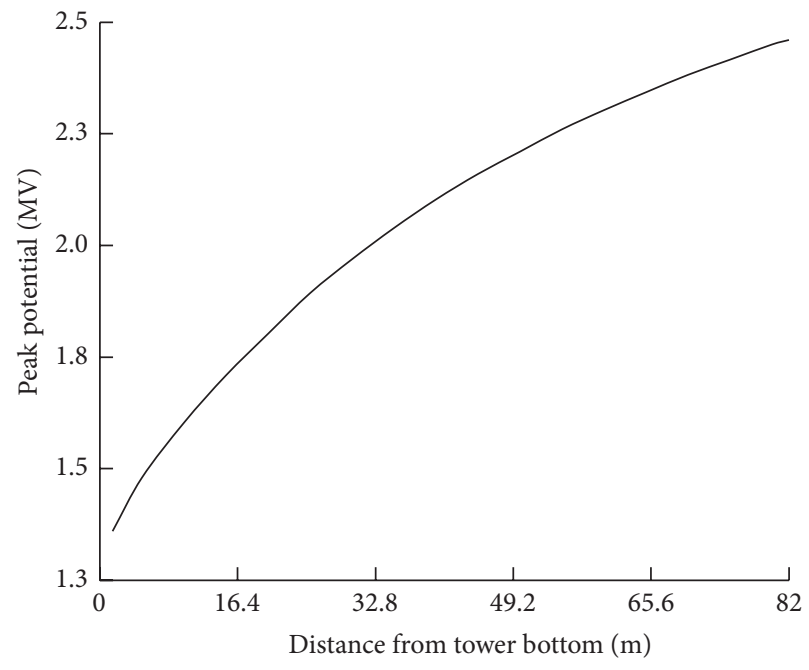

(a)

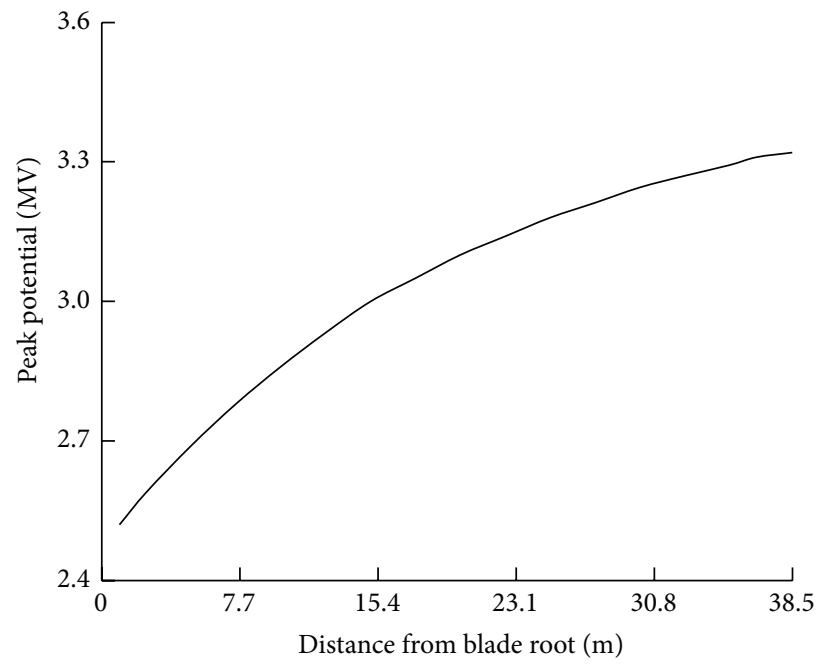

(b)

FIGURE 12: Peak potential distribution. (a) On tower. (b) On blade.

\section{Calculated Results}

A 2MW Chinese-built WT is considered here. The dimensions of the WT are $l_{b}=38.5 \mathrm{~m}$ (see Figure 1 ), $l_{t}=82 \mathrm{~m}$, $r_{1}=1.35 \mathrm{~m}, r_{2}=2.16 \mathrm{~m}$, and $w=0.025 \mathrm{~m}$ (see Figure 4 ). The grounding resistance $R_{g}$ is $3 \Omega$ and the lightning current $i$ is taken as 10/350 $\mu \mathrm{s}, 100 \mathrm{kA}$ (see Figure 6) according to Chinese design standard $[15,19]$. The peak potential distribution on the WT is plotted in Figure 12. The transient potential waveforms in three typical positions on the WT are also given in Figure 13. As seen from Figures 12 and 13, the transient potential rise on the WT is very serious and can do damage to the components and equipment inside the structure during a lightning stroke.

\section{Conclusions}

Calculation of the transient potential rise has been performed for the WT under lightning stroke. The lightning current path on the WT is described by a proposed circuit model that integrates the blade, sliding contact site, and tower and grounding system into a complete equivalent circuit. The model can predict the transient potential levels in the different positions on the WT. The calculated results obtained from the model indicate that the transient potential rise is serious and very harmful to the components inside the structure during a lightning stroke. The validity of the model has been confirmed by the laboratory experiment on a reduced-scale WT. The model is useful in lightning transient 


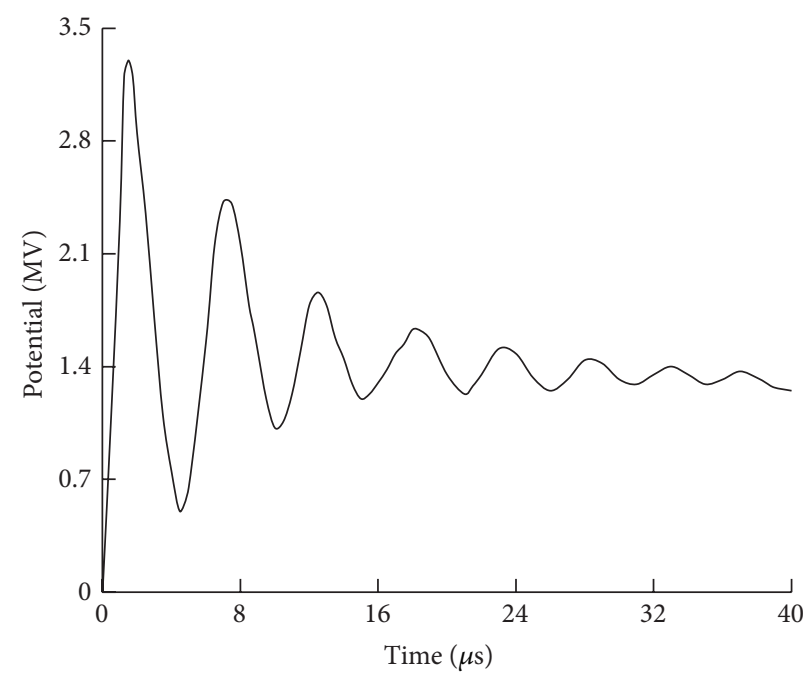

(a)

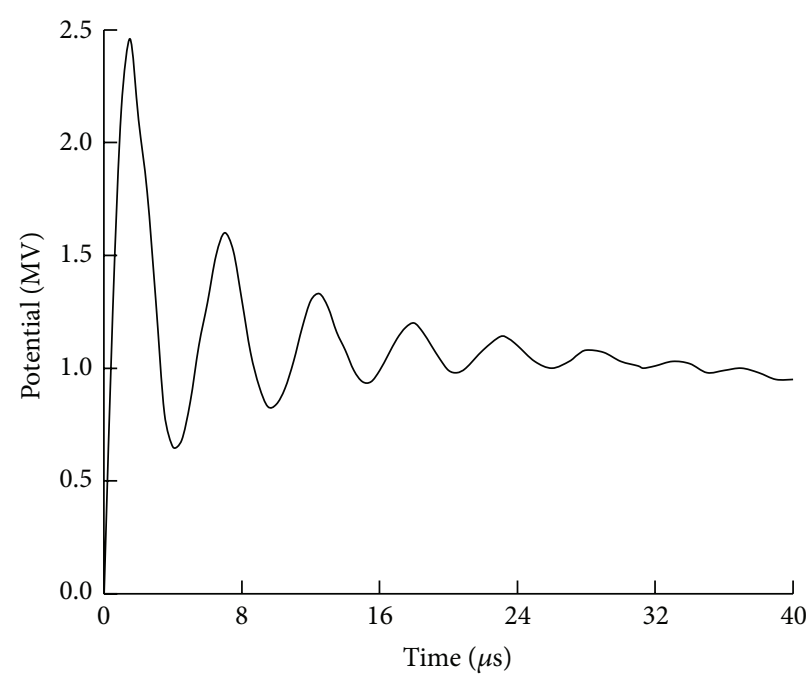

(b)

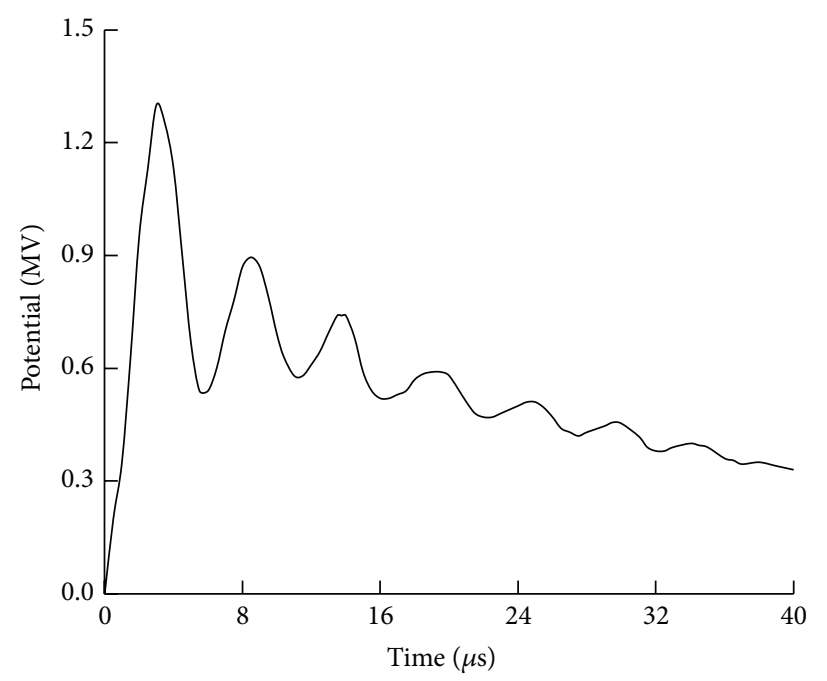

(c)

Figure 13: Transient potential waveforms. (a) At blade tip. (b) At tower top. (c) At tower bottom.

analysis of WTs and has the capability of providing a sound basis for the lightning protection design of WTs.

\section{Conflict of Interests}

The author declares that there is no conflict of interests regarding the publication of this paper.

\section{Acknowledgment}

This work was financially supported by National Natural Science Foundation of China under Award no. 509770926.

\section{References}

[1] R. B. Rodrigues, V. M. F. Mendes, and J. P. S. Catalão, "Analysis of transient phenomena due to a direct lightning strike on a wind energy system," Energies, vol. 5, no. 7, pp. 2545-2558, 2012.
[2] T. Q. Nguyen1, T. Pham, and T. V. Tran, "Electromagnetic transient simulation of lightning overvoltage in a wind form," in Proceedings of the Electrical Insulation Conference, Ottawa, Ontario, 2013.

[3] D. Romero, J. Montanyà, and A. Candela, "Behavior of the wind-turbines under lightning strikes including nonlinear grounding system," in Proceedings of the International Conference on Renewable Energy and Power Quality, Barcelona, Spain, March-April 2004.

[4] X. Q. Zhang and C. Liu, "Lightning transient modeling of wind turbine towers," International Review of Electrical Engineering, vol. 7, no. 1, pp. 3505-3511, 2012.

[5] X. Q. Zhang, Y. Z. Zhang, and C. H. Liu, "A complete model of wind turbines for lightning transient analysis," Journal of Renewable and Sustainable Energy, vol. 6, no. 1, Article ID 013113, 2014.

[6] G. Celli and F. Pilo, "EMTP models for current distribution evaluation in LPS for high and low buildings," in Proceedings 
of the 25th International Conference on Lightning Protection, Rhodes, Greece, September 2000.

[7] R. B. Standler, Protection of Electronic Circuits from Overvoltages, John Wiley \& Sons, New York, NY, USA, 1989.

[8] C. Z. Feng, Electromagnetic Field Theory, Higher Education Press, Beijing, China, 2002.

[9] A. Ametani, Y. Kasai, J. Sawada, A. Mochizuki, and T. Yamada, "Frequency-dependent impedance of vertical conductors and a multiconductor tower model," IEE Proceedings-Generation, Transmission and Distribution, vol. 141, no. 4, pp. 339-345, 1994.

[10] U. Y. Iosseli, A. S. Kothanof, and M. G. Stlyrski, Handbook of Capacitance Calculation, Energy Press, Moscow, Russia, 1987 (Russian).

[11] M. Paolone, F. Napolitano, A. Borghetti et al., "Models of windturbine main shaft bearings for the development of specific lightning protection systems," in IEEE Lausanne Power Tech, pp. 1-5, Lausanne, Switzerland, July 2007.

[12] A. H. M. Arnold, "The alternating-current resistance of tubular conductors," Journal of the Institution of Electrical Engineers, vol. 78, no. 473, pp. 580-596, 1936.

[13] V. T. Morgan, R. D. Findlay, and S. Derrah, "formula to calculate the skin effect in isolated tubular conductors at low frequencies," IEE Proceedings-Science, Measurement and Technology, vol. 147, no. 4, pp. 169-171, 2000.

[14] B. L. Kalentrarov and L. A. Zeitlin, Handbook of Inductance Calculation, Energy Press, Moscow, Russia, 1992 (Russian).

[15] Chinese Industrial Standard of Energy Source, "Technical specification for lightning protection system of wind turbines," Tech. Rep. NB/T 31039-2012, Standards Press of China, Beijing, China, 2012.

[16] H. W. Dommel, Electromagnetic Transients Program Theory Book, BPA, Portland, Ore, USA, 1995.

[17] L. V. D. Sluis, Transients in Power Systems, John Wiley \& Sons, New York, NY, USA, 2001.

[18] W. Shi, Overvoltage Calculation in Power Systems, High Education Press, Beijing, China, 2009.

[19] Chinese National Standard; GB 50057-2010, Design Code for Lightning Protection of Structures, China Planning Press, Beijing, China, 2010. 


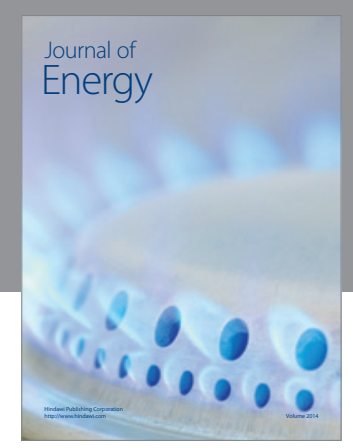

Journal of

Industrial Engineering
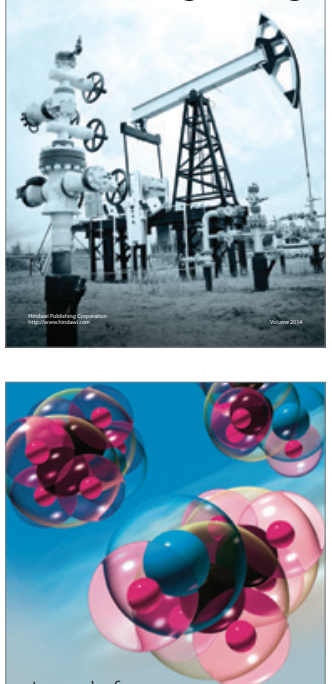

Fuels
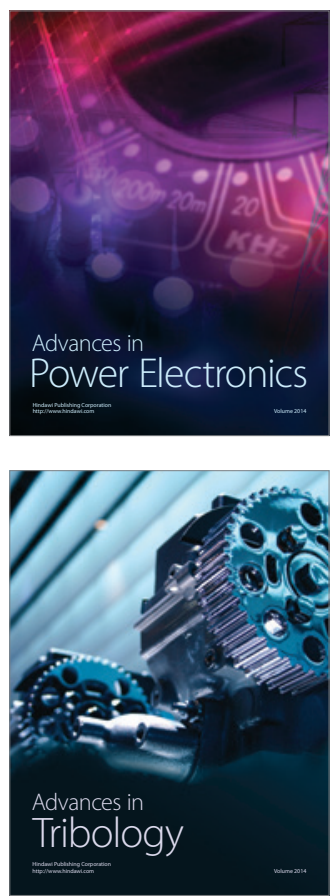

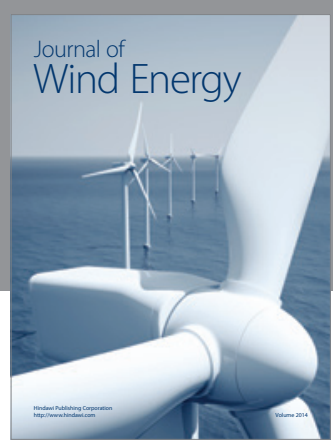

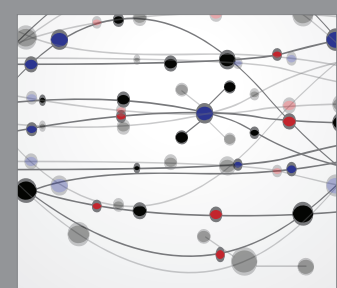

The Scientific World Journal

Submit your manuscripts at http://www.hindawi.com

Journal of

Structures
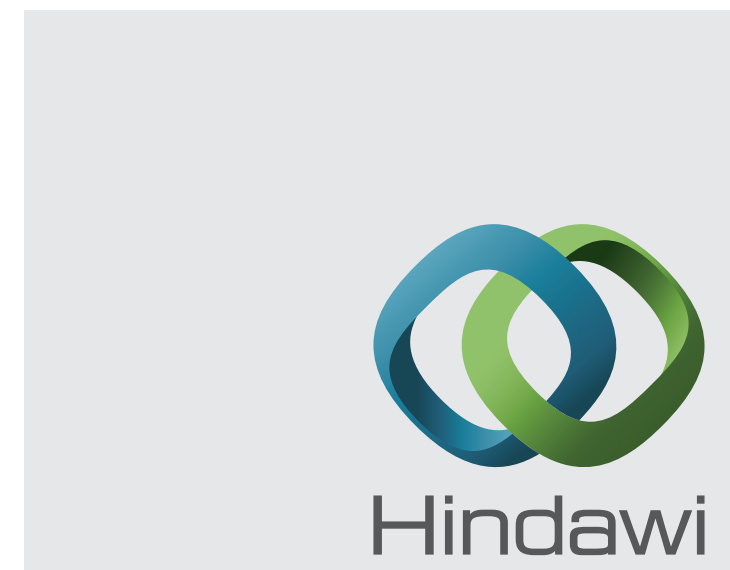

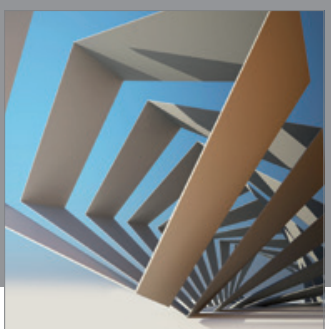

Rotating

Machinery
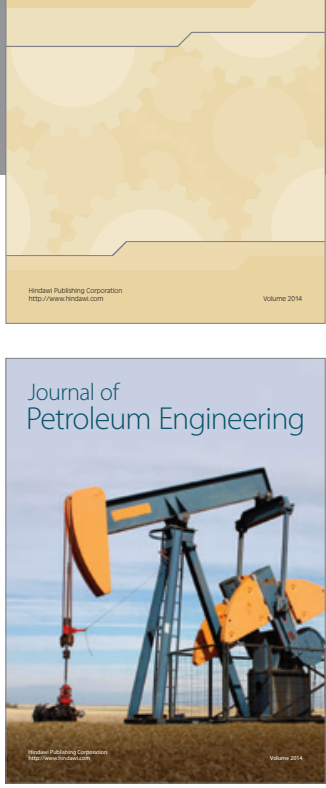

Journal of

Solar Energy
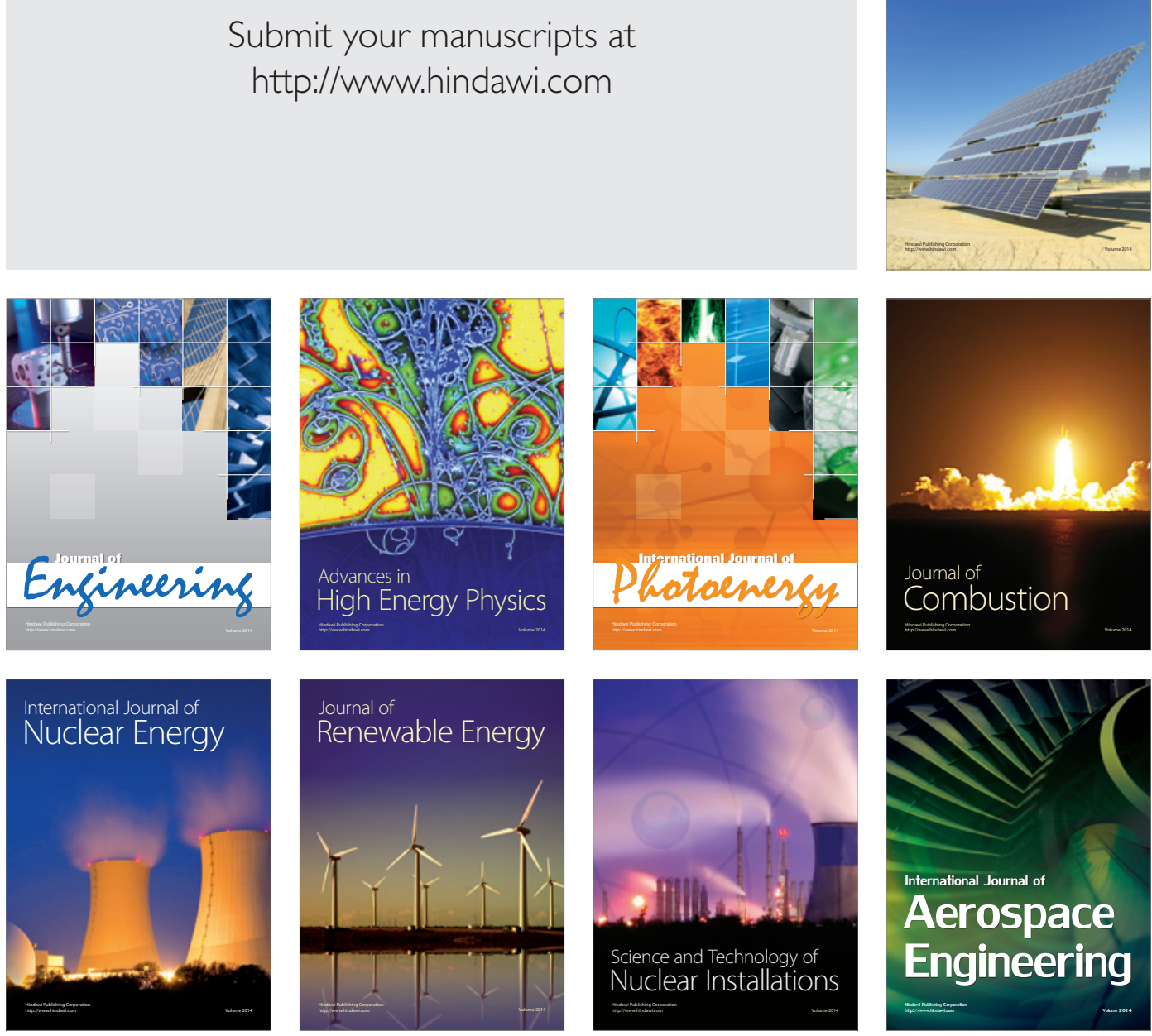